\title{
Efecto del perfil de caseínas, recuento de células somáticas y composición de la leche en el rendimiento del queso Dambo
}

\author{
Effect of caseins profile, somatic cells count \\ and milk composition in Dambo cheese yield
}

Escobar, Daniela (1), Pelaggio, Ronny (1), Grille, Lucía (2), Colzada, Enrique (3), Rampoldi, Cecilia (1), Carro, Silvana (2), Delucchi, Inés (4), Viola, Natalia (5), Nolla, Juan Pablo (6), Reinares, Rosana (1), Chilibroste, Pablo (3), Piedrabuena, Laura (7). (1) Gerencia de Investigación, Desarrollo e Innovación y Gerencia de Análisis, Ensayos y Metrología, Laboratorio Tecnológico del Uruguay, LATU - (2) Departamento de Ciencia y Tecnología de la Leche, Facultad de Veterinaria, UdelaR, Montevideo, Uruguay - (3) Departamento de Producción Animal y Pasturas (Bovinos de Leche), Facultad de Agronomía - Udelar, Montevideo, Uruguay - (4) INIA, Programa de Producción de Leche. Laboratorio de Calidad de Leche - (5) CLALDY S.A., Uruguay - (6) PILI S.A., Uruguay - (7) CRI Lechero del Litoral, Uruguay.

Contacto: descobar@latu.org.uy

RECIBIDO: 30/05/2014 - APROBADO: 15/10/2014

\begin{abstract}
Resumen
El rendimiento quesero influye en la competitividad de las industrias queseras, por lo que se busca producir leche de mayor valor y su mejor aprovechamiento. El conocimiento de la materia prima repercute en la toma de decisiones del productor y la industria.

El objetivo de este estudio fue analizar la influencia de la caseína, su perfil y otros componentes de la leche en el rendimiento del queso Dambo, producido a escala piloto e industrial, con leches provenientes del Litoral Noroeste uruguayo. A escala piloto se utilizaron condiciones de: alta caseína y bajo RCS, alta caseína y alto RCS, baja caseína y bajo RCS y baja caseína y alto RCS. En escala industrial se compararon los quesos de alta caseína con el promedio de planta. Se estudiaron dos estaciones. Se encontró que el queso Dambo elaborado con alta caseína $(>2,6 \mathrm{~g} / 100 \mathrm{~g})$ y bajo RCS $(<200.000 \mathrm{cel} / \mathrm{mil})$ tuvo un aumento de rendimiento del $10 \%$ respecto al de baja caseína $(<2,41 \mathrm{~g} / 100 \mathrm{~g})$ y alto RCS $(>500.000 \mathrm{cel} / \mathrm{mil})$, ocasionado por mayor recuperación de materia grasa en el queso. A escala industrial se obtuvo un aumento del $9 \%$ utilizando alta caseína en leche. Asimismo, existe una influencia positiva de la $\mathrm{k}-\mathrm{CN}$ y $ß-C N$ en el rendimiento quesero, con una asociación entre $a-C N$ y recuperación de materia grasa.

Palabras clave: Calidad de la leche, rendimiento quesero, textura, recuento de células somáticas, caseína.
\end{abstract}

\begin{abstract}
The yield of cheese affects the competitiveness of the dairy industry, so it is interesting to produce milk of higher value for a better profit. Knowledge of raw materials affects the decisions of producers and industry. The aim of this study was to analyze the influence of casein, its profile and other milk components in Dambo cheese yield, produced at pilot and industrial scale with milk from the Northwest Coast of Uruguay. In pilot-scale milk conditions were: high casein and low SCC, high casein and high SCC, low casein and low SCC and low casein and high SCC. In industrial scale high casein cheeses were compared with the average plant. Two seasons were studied. We found that Dambo cheese made with high casein $(>2,6 \mathrm{~g} / 100 \mathrm{~g})$ and low SCC $(<200.000 \mathrm{cel} / \mathrm{mil})$ had a performance increased by $10 \%$ compared to low-casein $(<2,41 \mathrm{~g} / 100 \mathrm{~g})$ and high SCC $(<500.000 \mathrm{cel} / \mathrm{mil})$, caused by an increased fat recovery in cheese.

In industrial scale an increase of $9 \%$ with high milk casein was obtained. There is also a positive influence of $\mathrm{k}-\mathrm{CN}$ and $\mathrm{B}-\mathrm{CN}$ in cheese yield, with an association between $\alpha-\mathrm{CN}$ and fat recovery.

Keywords: Milk quality, cheese yield, texture, somatic cells count, casein.
\end{abstract}

\section{Introducción}

Uno de los factores más importantes para las industrias productoras de queso y que influye decisivamente en la viabilidad económica es el rendimiento quesero. El rendimiento quesero juega un rol fundamental en la rentabilidad de las industrias lácteas, especialmente en el caso de las industrias del Litoral Norte uruguayo, donde el queso supone el $80 \%$ de sus exportaciones, lo que representó económicamente US\$ 61.374 .000 para el año 2011 (Uruguay XXI, 2012). Si bien el rendimiento depende de muchos factores vinculados al proceso industrial, la materia prima utilizada y su conocimiento en profundidad son factores fundamentales en la ecuación financiera de la industria quesera, que generan in- 
formación imprescindible para la toma de decisiones. Existen distintas formas de cálculo para el rendimiento quesero, no hay una manera única y correcta de predecirlo, ya que depende directamente de la composición de la leche, el tipo de queso y las condiciones de procesamiento. Algunos autores han discutido fórmulas, y tal vez una de las recopilaciones más completas es el boletín especial que publicó la IDF en el año 1993 (International Dairy Federation, 1993). Varios son los parámetros que impactan en la transformación de leche a queso, y el conocimiento de estos factores permitiría definir potenciales acciones que representen una ventaja competitiva para la industria quesera.

La leche es un fluido acuoso y complejo formado por diversas fases en equilibrio, en las que los factores fisicoquímicos, microbiológicos y enzimáticos afectan directamente la calidad y el rendimiento del producto final. Las caseínas ocupan el $80 \%$ de la fracción proteica de la leche y son de gran importancia para la tecnología de productos lácteos. En la transformación de la leche en queso, las caseínas $\left(\alpha_{\mathrm{s} 1}\right.$, $\alpha_{\mathrm{s} 2}, \beta$ y $\left.\kappa\right)$ forman la red proteica conocida como coágulo o gel que será determinante de la calidad y rendimiento del producto final. Se ha demostrado que las interacciones iónicas e hidrofóbicas mantienen la integridad estructural de la micela de caseína, así como la $\kappa$-caseína $(\kappa-\mathrm{CN})$ limita el proceso de asociación proteica, determinando el tamaño final y estabilidad de la micela (Kruif, et al., 2012; Huppertz, et al., 2006). A su vez, juega un rol tecnológico importante en la formación de la cuajada y el rendimiento final en la producción de queso. Tal es así, que leches con alta cantidad de proteínas pero con bajas propiedades para la elaboración de queso afectan el rendimiento (Ikonen, et al., 1999) en virtud del bajo contenido de caseína. Por ende, el rol que juegan las caseínas es fundamental a nivel tecnológico.

Las micelas de caseína están altamente hidratadas y varían en tamaño desde 50 a $300 \mathrm{~nm}$. El tamaño medio de las micelas de caseína nativas está influenciado por el régimen de alimentación del rodeo, sus genotipos de $\alpha_{s 1}-\mathrm{CN}$ y $\kappa-\mathrm{CN}$, el pH (Devold, et al., 2000) y la variación estacional. Glantz y equipo (2010) estudiaron la influencia del tamaño de la caseína en la formación de geles de renina, concluyendo que un menor tamaño de micela de caseína mejora las propiedades de gelificación, lo que podría optimizar el paso inicial en el procesamiento del queso.

Varios autores han evaluado el efecto de la composición de las distintas proteínas en las propiedades coagulantes de la leche, hallando una influencia de la $\kappa-\mathrm{CN}$ y su proporción en relación a la $\mathrm{CN}$ total, donde una baja concentración de $\kappa-\mathrm{CN}$ es asociada a una mala coagulación de la leche (Wedholm, et al., 2006), con su consecuente disminución en el rendimiento del queso. Existen estudios que han asociado el alelo B de la $\kappa-\mathrm{CN}$ como determinante para la buena coagulación de la leche, con la obtención de un cuajo más firme, reduciendo tiempos de coagulación de cuajada e incrementando el rendimiento del queso (Ng-Kwai-Hang, 1998; Wedholm, et al., 2006). También se constata un papel importante de la relación a-CN y $\beta$-CN como constituyentes básicos de la microestructura del queso (St-Gelais, et al., 2005) El mecanismo de coagulación de las micelas de caseína es un tema complejo y parte de esa complejidad depende de la naturaleza de la leche, su composición, calidad y microestructura.

Asimismo, las leches con un alto contenido de células somáticas se caracterizan por generar una alta concentración de proteasas y una alta actividad enzimática (Santos, et al.,
2003) que va en detrimento de la calidad y rendimiento de los quesos. Si bien existen factores indirectos que son relevantes, los mismos pueden ser detectados y controlados en el tambo y en la industria, entre otros: temperatura y tiempo de enfriamiento de la leche, exceso de agitación y bombeo, corte prematuro de cuajada, defecto de diseño de tina y liras, calibración de instrumentos de medición, tipo de cuajo utilizado, etcétera.

Ozymek y equipo (1993) sugirieron la optimización de la producción, dado que algunas leches son más adaptadas a la producción de queso, mientras que otras pueden ser más rentables económicamente si son utilizadas para el procesamiento de la leche fluida.

Por lo antedicho, es importante el estudio de la composición y calidad de la leche, especialmente la caseína. El conocimiento de los distintos sistemas de producción de leche así como de la variación estacional representa una ventaja para la industria, permitiéndole disponer de fundamentos para la toma de decisiones sobre el destino de la leche en la elaboración de productos lácteos.

Esta investigación se desarrolló en el marco de las acciones llevadas adelante por el Consorcio Regional de Innovación de la Cadena Láctea del Litoral (CRI Lechero del Litoral) en la región Noroeste de Uruguay, mediante el proyecto «Patrones de variación de la caseína en leche en el Litoral Noroeste: su relación con sistemas productivos y producto final», cofinanciado en conjunto con la Agencia Nacional de Investigación e Innovación (ANII). El CRI Lechero del Litoral es una alianza público-privada integrada por: PILI S.A., CLALDY S.A., LATU, INIA y UdelaR, la cual tiene como finalidad efectuar investigación y desarrollos tecnológicos que contribuyan a mejorar la competitividad de la cadena láctea. Este proyecto generó un impacto a nivel de dicha cadena, por medio del conocimiento de la composición de la leche y su relación con la alimentación animal, variaciones climáticas, higiene de establecimiento, sanidad animal, etcétera. El objetivo de este trabajo fue analizar la influencia de la caseína, su perfil y otros componentes de la leche en el rendimiento de un queso tipo Dambo, producido a escala piloto e industrial, con leches provenientes de la región Litoral Noroeste de Uruguay.

\section{Materiales y Métodos}

\section{Selección de condiciones para el estudio de rendimiento quesero}

Para el estudio del rendimiento quesero de la leche se realizaron pruebas experimentales a escala piloto en la planta piloto del LATU y pruebas industriales en dos industrias del Litoral Oeste del Uruguay. En ambos casos se realizaron elaboraciones en dos estaciones del año (invierno y otoño).

\section{Escala piloto}

Para la evaluación de rendimiento en escala piloto se conformaron cuatro grupos experimentales, según la composición de caseína y parámetros higiénicos sanitarios, como el recuento de células somáticas (RCS) y el recuento de bacterias totales (RBT). La selección de productores se realizó en base a la evaluación de los distintos parámetros obtenidos 
a lo largo de un año sobre la composición de la leche y los parámetros higiénicos sanitarios de 30 establecimientos de leche de las dos industrias de la zona del litoral Oeste. En el año de investigación el $90 \%$ de los productores estudiados presentaron valores de RBT menores a $50.000 \mathrm{ufc} / \mathrm{mL}$, por lo que la selección para el estudio fue realizada según la caseína y el recuento de células somáticas. Los productores se seleccionaron para los tratamientos estadísticos según: 1) alta caseína y bajo RCS, 2) alta caseína y alto RCS, 3) baja caseína y bajo RCS, y 4) baja caseína y alto RCS.

Cada condición se realizó por cuatriplicado con leche de 8 productores en las dos estaciones del año que abarca el estudio. Se tomó leche por duplicado de cada uno de los 16 productores para cada elaboración de queso.

\section{Escala industrial}

Para las pruebas industriales se utilizó para comparar el rendimiento quesero la composición de caseína de la leche, debido a que es un parámetro que se puede obtener rápidamente en planta si se tiene el equipo adecuado. Se efectuaron comparaciones elaborando quesos con leches de alta caseína contra el promedio de planta (testigo).

Se realizaron cinco repeticiones de cada condición (alta caseína y testigo). Cada industria eligió para la condición experimental de alta caseína un establecimiento con leche de alta caseína seleccionado de los 30 establecimientos analizados. El testigo era el que correspondía a la elaboración del silo de cada planta del día de elaboración.

\section{Elaboración de queso Dambo}

\section{Escala piloto}

Cada lote de queso fue elaborado a partir de $50 \mathrm{~L}$ de leche bovina cruda de cada establecimiento seleccionado. A la llegada de los lotes de leche se midió su temperatura, $\mathrm{pH}$ y acidez antes de la elaboración. La leche se estandarizó al $3,0 \%$ de materia grasa (MG), en descremadora Westfalia Separator modelo LWA 205-1 (Germany). El proceso de elaboración de los quesos se realizó en una tina quesera doble $\mathrm{O}$ con doble camisa y sistema de agitación y corte mecánico controlado, donde a partir de 50 L se pasteurizó inmediatamente a $72{ }^{\circ} \mathrm{C}$ por 15 segundos. Los quesos fueron elaborados el mismo día de la recepción de la leche. El proceso aplicado se muestra en la Figura 1.

Todos los quesos fabricados fueron envasados y conservados en la cámara de maduración hasta el momento de su análisis. Se analizaron los quesos a tiempo 0, 30, 60 y 120 días.

\section{Escala industrial}

Cada lote de queso en cada industria fue elaborado a partir de tinas industriales de $12.000 \mathrm{~L}$ de leche, midiéndose $\mathrm{pH}$ y densidad de la leche antes de la elaboración. Se estandarizó y se siguió el procesamiento habitual de elaboración de queso Dambo de las plantas procesadoras. Todos los quesos fueron envasados y conservados en cámara de maduración a 8 +/$2{ }^{\circ} \mathrm{C}$ hasta el momento de su análisis. La industria tomó el peso y la humedad a tiempo 0 en la planta industrial, y luego se realizaron los análisis en el LATU. La empresa A analizó los quesos a los 30, 60 y 120 días de madurados y la empresa $\mathrm{B}$ a los 60 y 120 días de madurados.

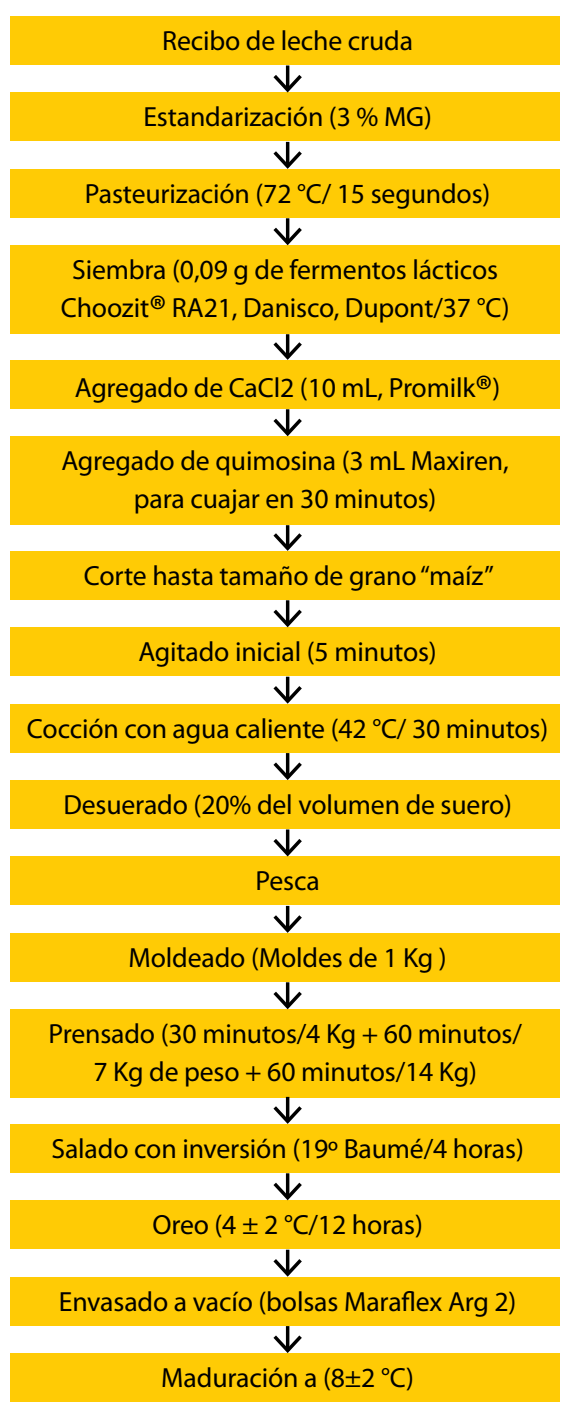

Figura 1. Proceso de elaboración de queso.

\section{Análisis de la leche}

Se efectuaron tanto en leche cruda como en leche de tina, con el siguiente detalle: $\mathrm{pH}$, acidez (como control de rutina), RCS, RBT fueron realizados a partir de la leche cruda, mientras que los parámetros de composición, densidad, y perfil de caseína fueron realizados en ambas leches. También se analizó el diámetro de micela de caseína, solo de las leches de tina correspondientes a la segunda elaboración. A continuación se detallan los análisis:

- $\quad$ pH: Se midió con pHmetro Mettler Toledo Seven Multi y electrodo combinado de penetración.

- Acidez titulable: En grados Dornic según ISO/TS 22113 (IDF/RM 204:2012).

- Composición de la leche. Proteínas, materia grasa, sólidos no grasos, urea, caseína total y lactosa: Se realizó utilizando metodología infrarroja mediante el equipo MilkoScan TM FT2 (Foss, Dinamarca), calibrado según métodos de referencia (ISO 8968/IDF 20:2001; ISO 1211/ IDF1; ISO 6731/IDF 21).

- Células somáticas: Realizado con equipo Foss somatic (Foss, Dinamarca). 
- Análisis de perfil proteico: Se determinó el contenido de a, ß у к-caseína por cromatografía líquida de alta resolución (HPLC) de fase reversa (fase móvil polar), empleando detector PDA y extracción de cromatograma a $\lambda=222$ $\mathrm{nm}$, por porcentaje relativo de áreas (Bonizzi, et al., 2009).

- Distribución del tamaño de micela de caseína: Se utilizó analizador de tamaño de partículas por tecnología de difracción láser Zetasizer (Malvern Instruments Limited, UK). Se calculó el percentil $50 \% \mathrm{D}(\mathrm{v} 0,5)$, que es la mediana de la distribución, es decir, el valor de tamaño de partícula que divide a la población de gotas de la emulsión en dos partes iguales, $50 \%$ por encima y $50 \%$ por debajo. El valor de $\mathrm{D}(\mathrm{v} 0,9)$ representa el valor del tamaño de las partículas para que la distribución de estas sea exactamente el $90 \%$ de las partículas de la muestra (v/v) que presentan un tamaño inferior o igual.

\section{Análisis de los quesos}

En cuanto a los quesos, se aplicaron los siguientes análisis para medir rendimiento y textura:

- Peso: Se utilizó balanza de precisión Shimadzu BX22KH.

- $\mathrm{pH}$ : Se midió con pHmetro Mettler Toledo Seven Multi y electrodo combinado de penetración I.

- Humedad, proteínas, materia grasa: Se analizaron con Food Scan ${ }^{\circledR}$ Lab type 78800 Foss, Dinamarca, previamente calibrado según las normas ISO 5534/ IDF 004:2004, ISO 8968/IDF 20:2001 e ISO 1735/IDF 005:2004, respectivamente.

- Textura: Se realizó el análisis de perfil de textura (TPA) con texturómetro TA-XT-Plus Texture Analyser (Stable Micro Systems Ltd., Godalmingel, UK). Se utilizaron muestras cortadas en cilindros de $17 \mathrm{~mm}$ de diámetro y $20 \mathrm{~mm}$ de largo a $20 \pm 2{ }^{\circ} \mathrm{C}$. Las muestras se sometieron a doble ciclo de compresión uniaxial con probeta cilíndrica de aluminio $\mathrm{P} / 36 \mathrm{R}$, velocidad $5 \mathrm{~mm} / \mathrm{s}$, compresión $35 \%$, tiempo de pausa 5 s. Se determinó la fuerza, elasticidad, cohesividad y masticabilidad y adhesividad. Fueron analizadas seis repeticiones por muestra. Para la adquisición de datos y cálculos se utilizó el software Exponent Stable Micro Systems Version 5.1.1.0.

\section{Cálculos de rendimiento y aprovechamiento de sólidos en queso}

Se tomó en cuenta el rendimiento económico y rendimiento práctico/técnico, para los cuales existen distintas ecuaciones según los contenidos de los componentes de la leche, los que determinarían si hubo un aprovechamiento ideal de los constituyentes de la leche que pueden ser transferidos al queso. Además, los cálculos de rendimiento quesero permitirían establecer comparaciones válidas entre diferentes fabricaciones de un mismo tipo de queso, a pesar de que estos presenten composición físico-química diferente.

Rendimiento Práctico/Técnico/Económico (R.E): es el resultado del cociente entre el peso del queso y el peso de la leche. Su ecuación es:

Rend. técnico o económico (R.E) \% $=\frac{\text { Peso queso }(\mathrm{Kg})}{\text { Peso leche }(\mathrm{Kg})} \times 100$
Rendimiento FIL (R.FIL): Rendimiento teórico basado en la composición de la leche cuya fórmula obtenida por Van Slyke y Publow y modificada por la International Dairy Federation (1993) incluye el contenido de materia grasa y caseína de la leche, factor de conversión de la grasa de la leche al queso y el contenido de humedad del queso.

Rendimiento FIL (R. FIL)

(R. FIL $) \%=\frac{\left(\mathrm{RMG}^{\star} \mathrm{MG}(\text { leche })+0.94\left(0.97{ }^{\star} \mathrm{CN}(\text { leche })\right)+0.78\right)^{\star} 100}{100-\mathrm{Hq}(\text { queso })}$

Donde:

RMG: recuperación de materia grasa.

MG: \% de materia grasa de la leche.

$\mathrm{CN}: \%$ de caseína de la leche.

Hq: \% de humedad en queso.

Rendimiento ajustado: Se utiliza para comparar el rendimiento quesero de quesos con diferentes tenores de humedad. La pregunta a la que responde la siguiente ecuación es: ¿ $\mathrm{Si}$ los quesos tuviesen el mismo tenor de humedad, el rendimiento sería el mismo? Se tomó como humedad de referencia $46 \%$.

Rend. ajustado (R. Aj) \% $=\frac{\mathrm{R}(100-\text { Hq. obtenida })}{(100-\text { Hq. de referencia })}$

El aprovechamiento de los sólidos de la leche en el queso se determinó mediante:

\section{Recuperación de materia grasa (RMG)}

$(\mathrm{RMG})=\frac{\text { Peso del queso }{ }^{\star} \mathrm{MGq} \text { (queso) }}{\text { Peso de la leche }{ }^{\star} \mathrm{MG} \text { (leche) }}$

Recuperación de proteína (RP)

$(\mathrm{RP})=\frac{\text { Peso del queso }{ }^{\star} \mathrm{Pq} \text { (queso) }}{\text { Peso de la leche }{ }^{\star} \mathrm{P} \text { (leche) }}$

\section{Recuperación de extracto seco (RES)}

$($ RES $)=\frac{\text { Peso del queso }{ }^{\star} \text { ESq (queso) }}{\text { Peso de la leche }{ }^{\star} \text { ES (leche) }}$

Donde:

MGq: \% de materia grasa del queso.

ESq: \% extracto seco del queso.

Pq queso: \% de proteína del queso.

P: \% de proteína de la leche.

ES: \% de extracto seco de la leche.

\section{Análisis de datos}

Para el análisis de rendimiento en escala piloto se utilizó un diseño experimental completamente al azar y se realizó un ANOVA de dos factores con interacción (tratamiento según la condición de caseína y células somáticas y estación del año). Para los estudios de las recuperaciones de proteína, materia grasa y extracto seco, así como para el de variación de la textura con el tiempo de maduración, el análisis estadístico se realizó según diseño al azar con parcelas divididas medidas en el tiempo utilizando ANOVA. Para el análisis de otros 
componentes de la leche se aplicó análisis multivariado de mínimos cuadrados parciales. Para determinar la diferencia significativa entre muestras se utilizó el test de Tukey $(\alpha \leq$ $0.05)$. Todos los análisis estadísticos fueron realizados usando InfoStat Statistical Software versión 2011.

\section{Resultados}

\section{Rendimiento}

Se realizó una comparación de las tres formulaciones de rendimiento quesero, propuestas en materiales y métodos, de las cuales algunas de ellas son de uso habitual en la industria quesera. En el Gráfico 1 (a y b) se muestran los rendimientos según la formulas FIL, ajustado y económico, de todos los lotes de elaboración.

a.

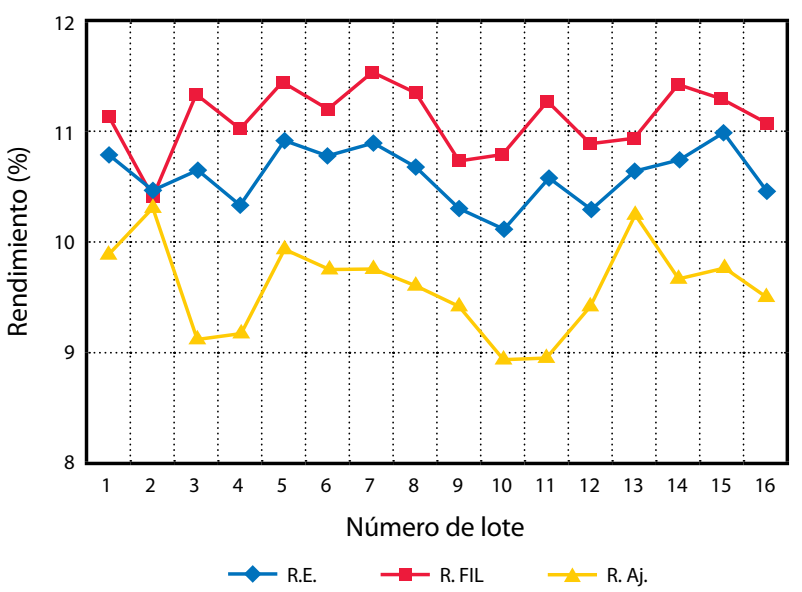

b.

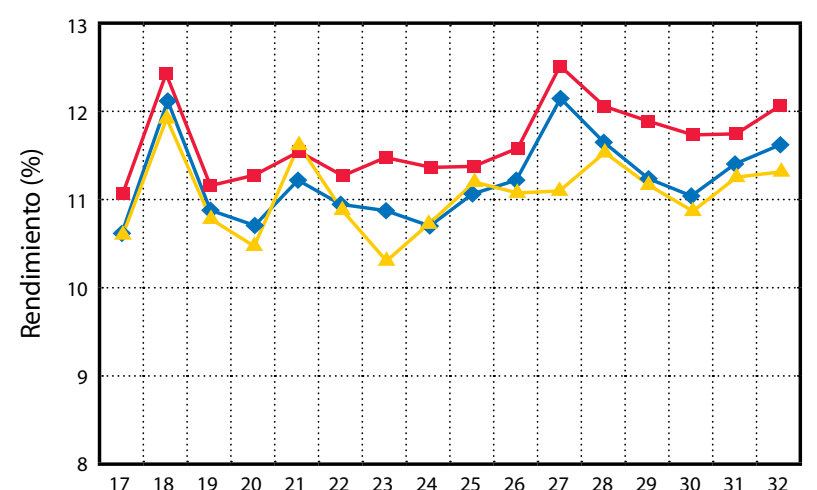

Número de lote

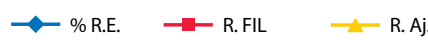

Gráfico 1. Rendimientos de todos los lotes de producción realizados en las elaboraciones de quesos de invierno (a) y otoño (b).

En ambos gráficos se observa una correlación entre la utilización del rendimiento FIL y el económico, no siendo así para el rendimiento ajustado, para el cual se corroboró una correlación lineal entre el rendimiento FIL y el económico por el método de regresión lineal $\left(\mathrm{p} \leq 0,001\right.$ y $\left.\mathrm{R}^{2}=0,91\right)$. El rendimiento FIL presentó correlación con el rendimiento económico, según las siguientes ecuaciones: R.FIL $=2,14$ $+0,85^{\star}$ R.E y R.FIL $=1,83+0,88^{\star}$ R.E en invierno y otoño, respectivamente.

No se verifica correlación del rendimiento ajustado con los otros rendimientos estudiados.

\section{Efecto de la caseína y el RCS en leche sobre el rendimiento quesero}

\section{Escala piloto}

Se presentan en la Tabla 1 los resultados del rendimiento técnico según fórmula FIL y el rendimiento económico o bruto de los cuatro grupos seleccionados para este estudio según la composición de caseína y el recuento de células somáticas en las dos elaboraciones y la correspondiente estación del año.

\begin{tabular}{|c|c|c|c|}
\hline $\begin{array}{c}\text { Caseína } \\
\text { y RCS }\end{array}$ & Estación & R. FIL (\%) & R.E (\%) \\
\hline $\begin{array}{c}\text { Alta CN } \\
\text { y alto RCS }\end{array}$ & Otoño & $11,97+/-0,17 c$ & $11,35+/-0,20 c$ \\
\hline $\begin{array}{c}\text { Alta CN } \\
\text { y bajo RCS }\end{array}$ & Otoño & $11,45+/-0,17 c$ & $10,88+/-0,20 c$ \\
\hline $\begin{array}{c}\text { Alta CN } \\
\text { y alto RCS }\end{array}$ & Invierno & $11,16+/-0,17 \mathrm{ab}$ & $10,62+/-0,20 \mathrm{abc}$ \\
\hline $\begin{array}{c}\text { Alta CN } \\
\text { y bajo RCS }\end{array}$ & Invierno & $11,28+/-0,15 \mathrm{a} \mathrm{b} c$ & $10,73+/-0,17 \mathrm{abc}$ \\
\hline $\begin{array}{c}\text { Baja CN } \\
\text { y alto RCS }\end{array}$ & Invierno & $11,05+/-0,17 \mathrm{ab}$ & $10,40+/-0,20 \mathrm{ab}$ \\
\hline $\begin{array}{c}\text { Baja CN } \\
\text { y bajo RCS }\end{array}$ & Invierno & $10,94+/-0,15 \mathrm{a} \mathrm{b}$ & $10,46+/-0,17 \mathrm{ab}$ \\
\hline $\begin{array}{c}\text { Baja CN } \\
\text { y alto RCS }\end{array}$ & Otoño & $10,73+/-0,17 \mathrm{ab}$ & $9,90+/-0,20 a$ \\
\hline $\begin{array}{c}\text { Baja CN } \\
\text { y bajo RCS }\end{array}$ & Otoño & $10,61+/-0,15 \mathrm{a}$ & $10,10+/-0,17 \mathrm{ab}$ \\
\hline
\end{tabular}

Tabla 1. Rendimientos de los quesos en las elaboraciones realizadas en las dos estaciones estudiadas según contenido de caseína y las células somáticas $(\mathrm{n}=4)$.

Medias con una letra común en la misma columna no son significativamente diferentes ( $\mathrm{p}>0,05)$.

Se encontró que existe diferencia significativa en el rendimiento quesero por un efecto de la caseína, independientemente de las células somáticas en el rendimiento FIL ( $\mathrm{p}$ - = $0,003)$ y en el rendimiento económico $(\mathrm{p}=0,009)$. En ambos rendimientos hubo interacción con las estaciones estudiadas ( $\mathrm{p}=0,0099$ y $\mathrm{p}=0,0239$, respectivamente). En el estudio realizado en otoño las células somáticas presentaron como valores promedios: alto RCS de $443 \mathrm{mil} / \mathrm{mL}$ y bajo RCS de $183 \mathrm{mil} / \mathrm{mL}$. En el caso de las caseínas se obtuvieron valores promedios de alta y baja caseína de $2,60 \%$ y $2,40 \%$, respecti- 


\section{Escala industrial}

\begin{tabular}{|c|c|c|c|c|}
\hline \multirow{2}{*}{ EMPRESA } & CONDICIÓN & ESTACIÓN & R. FIL $(\%)$ & R. E (\%) \\
\hline \multirow{3}{*}{$\begin{array}{c}\text { EMPRESA } \\
\text { A }\end{array}$} & ALTA CN & INVIERNO & $9,49+/-0,09 \mathrm{a}$ & $9,46+/-0,10 \mathrm{a}$ \\
& TESTIGO & $9,33+/-0,09 \mathrm{a}$ & $9,28+/-0,10 \mathrm{a}$ \\
& ALTA CN & \multirow{2}{*}{ OTONO } & $10,06+/-0,09 \mathrm{~b}$ & $9,94+/-0,09 \mathrm{~b}$ \\
& TESTIGO & & $9,56+/-0,09 \mathrm{a}$ & $9,32+/-0,09 \mathrm{a}$ \\
\hline \multirow{2}{*}{$\begin{array}{c}\text { EMPRESA } \\
\text { B }\end{array}$} & ALTA CN & \multirow{2}{*}{ INVIERNO } & $10,94+/-0,08 \mathrm{~B}$ & $10,76+/-0,08 \mathrm{~B}$ \\
& TESTIGO & & $10,11+/-0,08 \mathrm{~A}$ & $10,03+/-0,08 \mathrm{~A}$ \\
& ALTA CN & \multirow{2}{*}{ OTOÑO } & $12,49+/-0,10 \mathrm{~B}$ & $12,04+/-0,10 \mathrm{~B}$ \\
\hline
\end{tabular}

Tabla 2. Rendimientos de los quesos realizados industrialmente en las empresas A y B según cada estación $(\mathrm{n}=5)$. Medias con una letra común en la misma columna no son significativamente diferentes ( $p>0,05)$.

vamente. En la Tabla 1 se observa una diferencia significativa al 5\% de confianza entre los rendimientos queseros obtenidos a partir de leches con alta y baja caseína en las elaboraciones de otoño, independientemente del valor de células somáticas, en el rango trabajado.

Para los quesos elaborados en invierno el mayor rendimiento se obtuvo con la utilización de leche de alta caseína y bajo RCS. En esta estación las diferencias entre los valores promedios de caseína de las leches que se utilizaron por cada condición fueron menores: alta caseína 2,56\% y baja caseína $2,41 \%$. En cuanto al RCS presentaron un promedio de alto RCS $491 \mathrm{mil} / \mathrm{mL}$ y bajo RCS $221 \mathrm{mil} / \mathrm{mL}$.

Se expresan en la Tabla 2 los rendimientos obtenidos por las dos empresas en ambas estaciones del año de estudio. En la empresa A se observó un aumento significativo $(\mathrm{p} \leq 0,05)$ en el rendimiento al utilizar alta caseína contra el testigo de planta solo en otoño, que en el caso del rendimiento económico representa un $6,6 \%$. A su vez, los estudios realizados en invierno solo tuvieron en el caso del rendimiento FIL una diferencia significativa al $10 \%$ de confianza ( $\mathrm{p}=0,086)$ aumentando un $1,9 \%$. En tanto, en la empresa $B$ se obtiene un aumento significativo del rendimiento por el uso de leche con alta caseína contra el testigo de planta en las dos estaciones de estudio, con un aumento del $7 \%$ en invierno y del $18 \%$ en otoño. Luego de los resultados obtenidos en invierno, la empresa B realizó cambios que permitieron mejorar el aumento del rendimiento en otoño. En ambas empresas y en todos los casos estudiados la caseína del silo promedio de la planta siempre tuvo valores menores de caseína que los silos que se utilizaron para leche con alta caseína.

\section{Aprovechamiento de los sólidos de la leche en el queso}

\section{Escala piloto}

Se presentan los resultados de aprovechamiento de los sólidos según la recuperación de materia grasa, proteína de la leche en a.

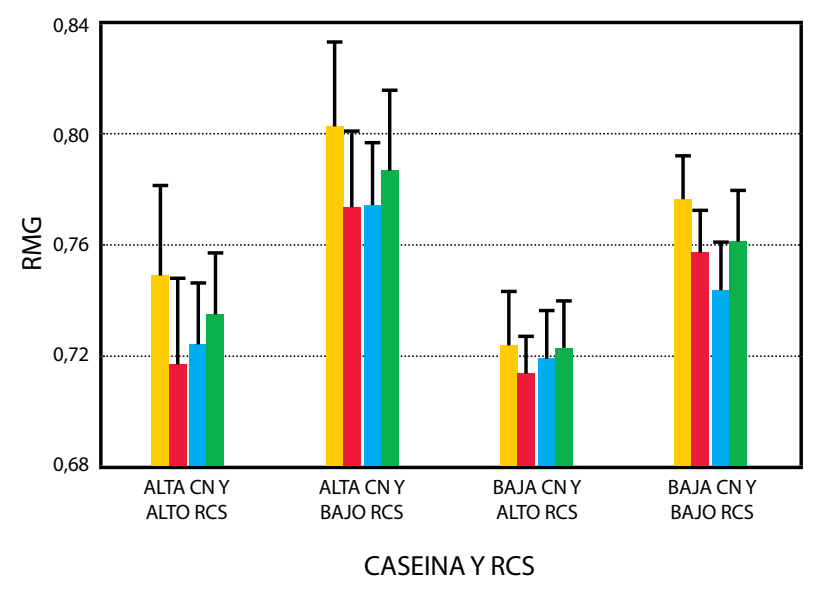

b.

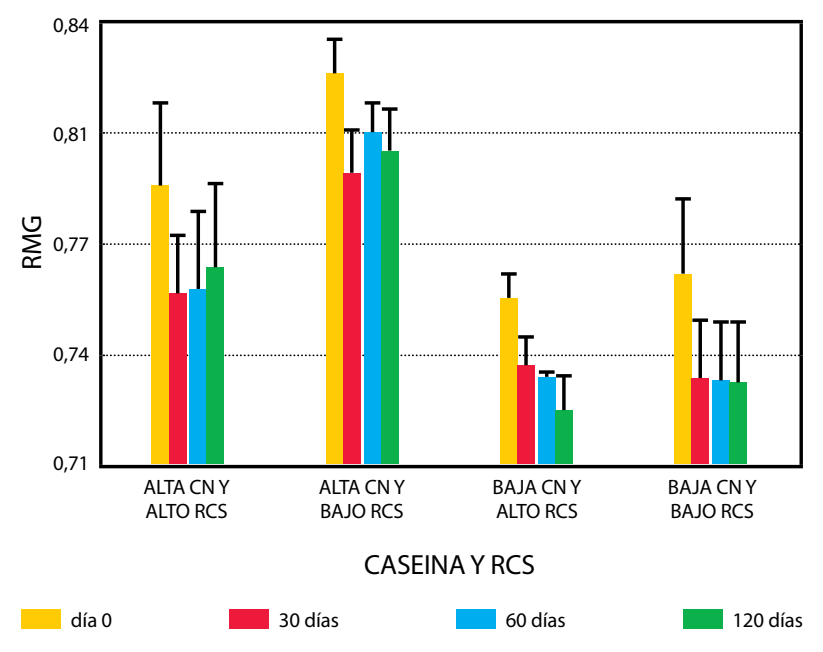

el queso (Gráficos 2, 3 y 4) y la humedad de los quesos según las elaboraciones realizadas por estación del año. 
Gráfico 2. Recuperación de materia grasa de leche en quesos elaborados en invierno (a) y otoño (b) con el tiempo.

En los quesos fabricados en ambas estaciones se observa que las leches con alta caseína y bajo recuento de células somáticas presentaron mayor recuperación de materia grasa que el resto de las leches $(\mathrm{p} \leq 0,05)$, sin registrarse diferencias en el tiempo.

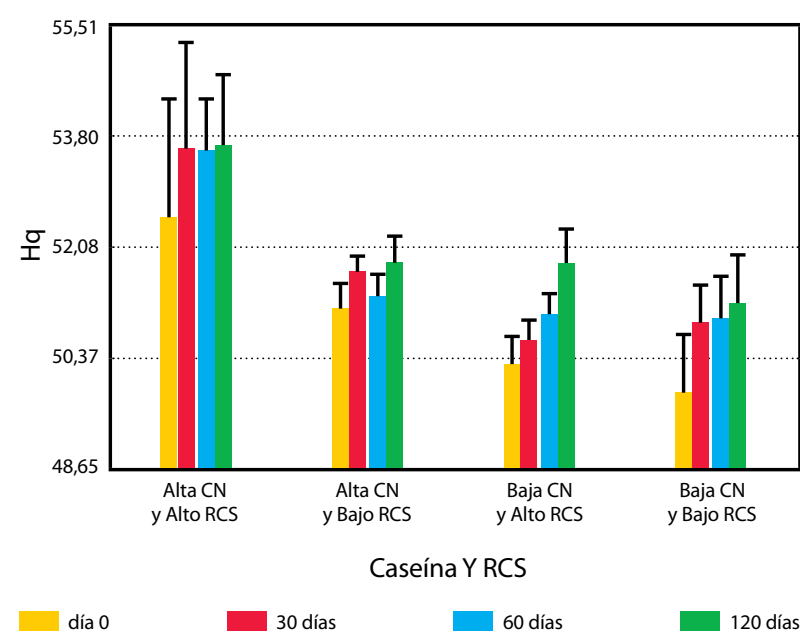

Gráfico 3. Humedad en quesos en función del tiempo de la elaboración realizada en otoño.

En cuanto a la humedad de los quesos, en las elaboraciones de invierno no se encontraron diferencias significativas en la humedad, pero sí hubo diferencias entre los tratamientos estudiados en los quesos elaborados en otoño, como se muestra en el Gráfico 3.

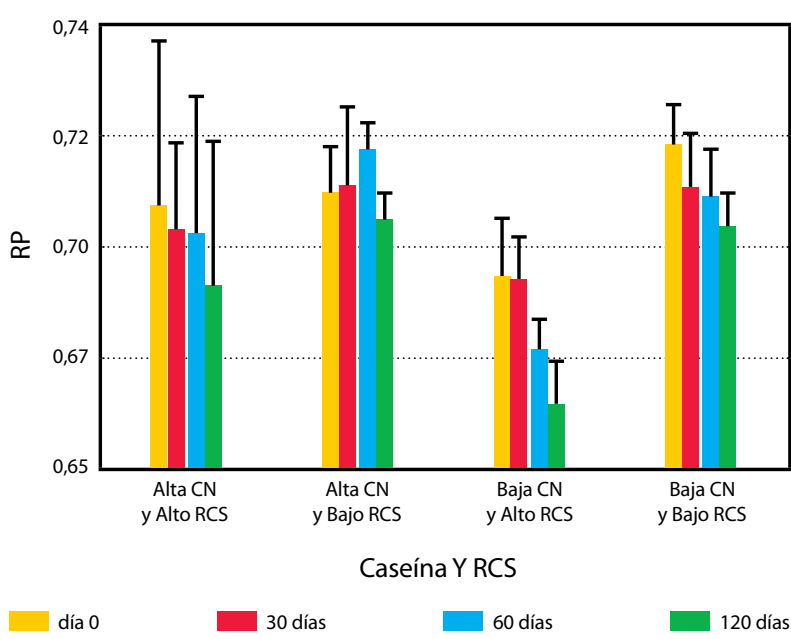

Gráfico 4. Recuperación de proteínas de la leche en quesos con el tiempo de la elaboración realizada en otoño.

En el Gráfico 4 se presenta la recuperación de las proteínas de la leche en el queso en otoño. Se determinó que las leches con baja caseína y alto recuento de células somáticas presentaron menor recuperación de proteína $(\mathrm{p} \leq 0,05)$. Las leches con altos recuentos de células somáticas (indicador del estado de salud de la glándula mamaria) estarían indicando un aumento en la actividad de la plasmina, afectando las proteínas.

\section{Escala industrial}

En el Gráfico 5 ( $a$ y b) se expresan las recuperaciones de materia grasa obtenidas en las elaboraciones industriales de la empresa A, en cada estación del año.

a.

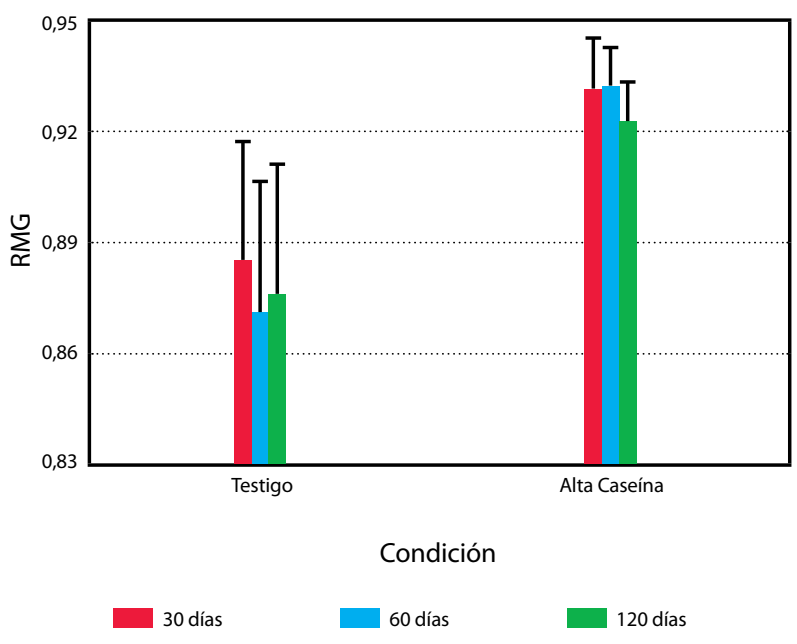

b.

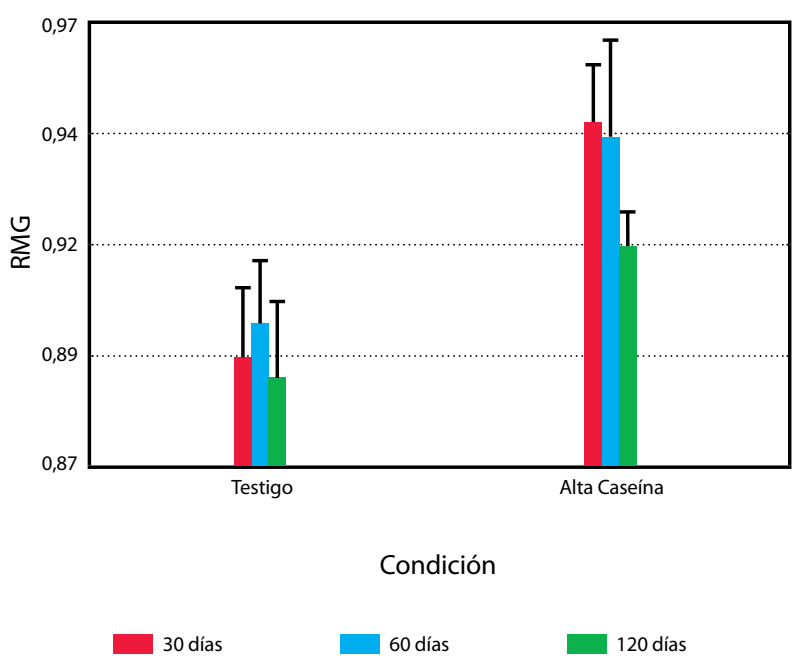

Gráfico 5. Recuperación de materia grasa de la leche en los quesos elaborados en invierno (a) y otoño (b) con el tiempo de la empresa A.

En ambas estaciones se observó que las leches con alta caseína de la empresa A presentaron mayor recuperación de materia grasa que el testigo de planta $(\mathrm{p} \leq 0,05)$.

A su vez, no se encontraron diferencias significativas en la empresa A en la recuperación de proteínas, ni en la humedad del queso en ambas estaciones entre el testigo y alta caseína. 
a.

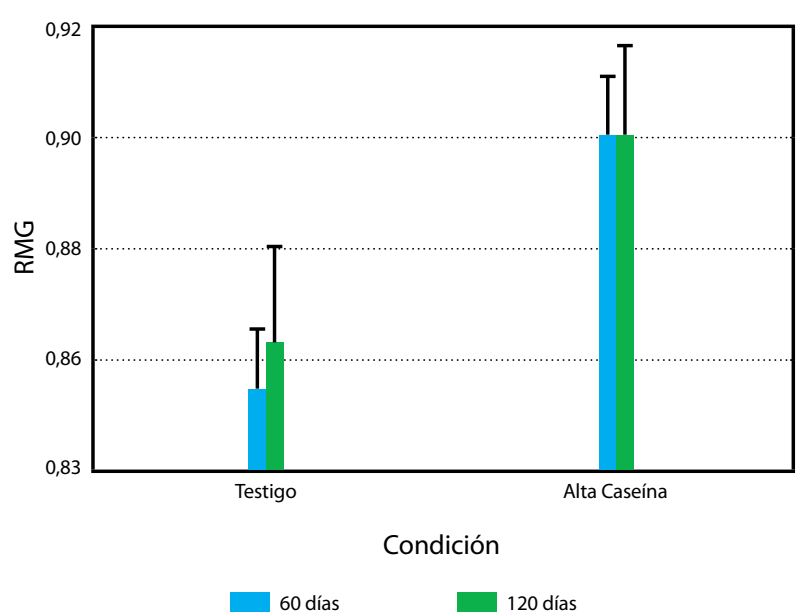

b.

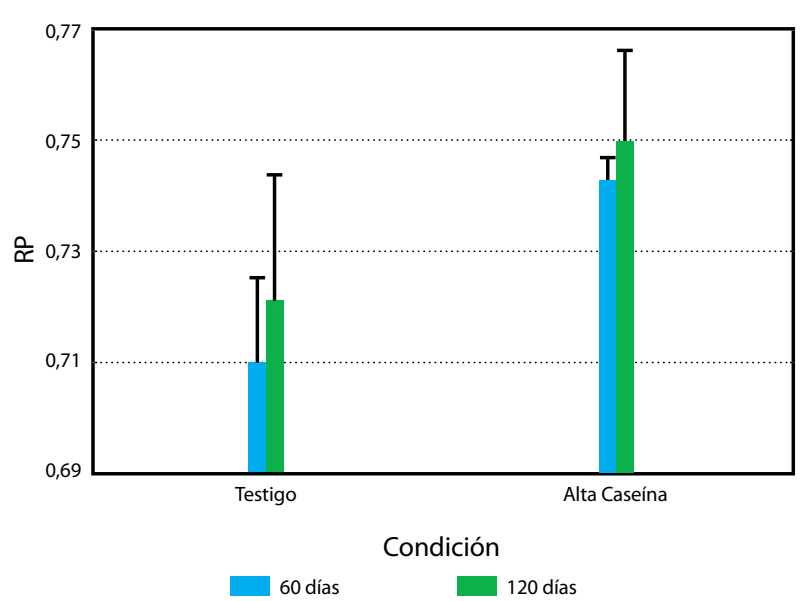

Gráfico 6. Recuperación de materia grasa (a) y de proteína (b) en invierno con el tiempo de la empresa B.

En las elaboraciones de la empresa B se observó que las leches con alta caseína presentaron mayor recuperación de materia grasa y de proteína que el testigo de planta $(\mathrm{p} \leq 0,05)$, sin diferencias significativas en el tiempo. No se hallaron diferencias por la humedad de los quesos en las elaboraciones entre el testigo y alta caseína, tampoco en el tiempo.

\section{Efecto de distintos componentes de la leche en el rendimiento quesero}

Se muestra en el Gráfico 7 ( $\mathrm{a}$ y b) la influencia de los distintos componentes de la leche, como la proteína, materia grasa, urea, caseína, lactosa, así como también el perfil de caseínas ( $\alpha-\mathrm{CN}, \beta-\mathrm{CN}$ y $\kappa-\mathrm{CN})$ y las células somáticas según el rendimiento quesero, humedad del queso y recuperación de materia grasa de las elaboraciones realizadas en invierno y otoño. a.

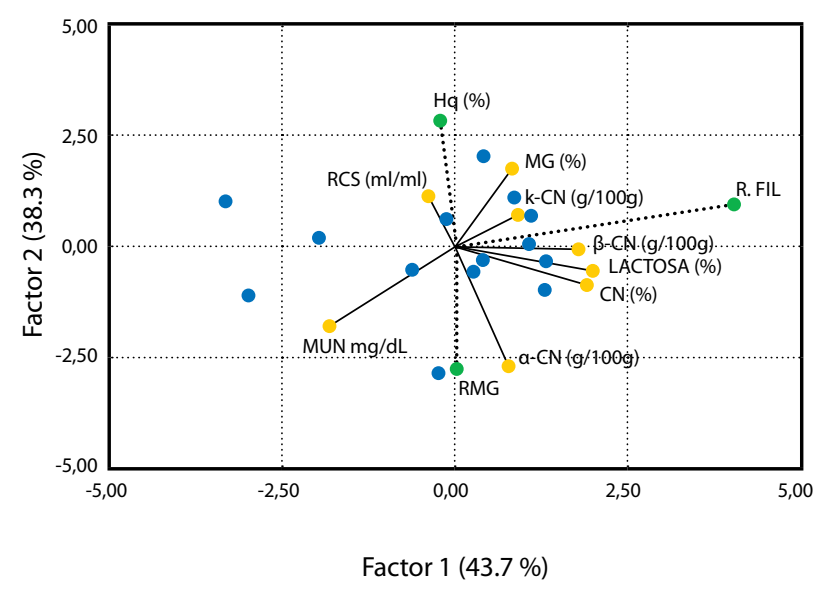

b.

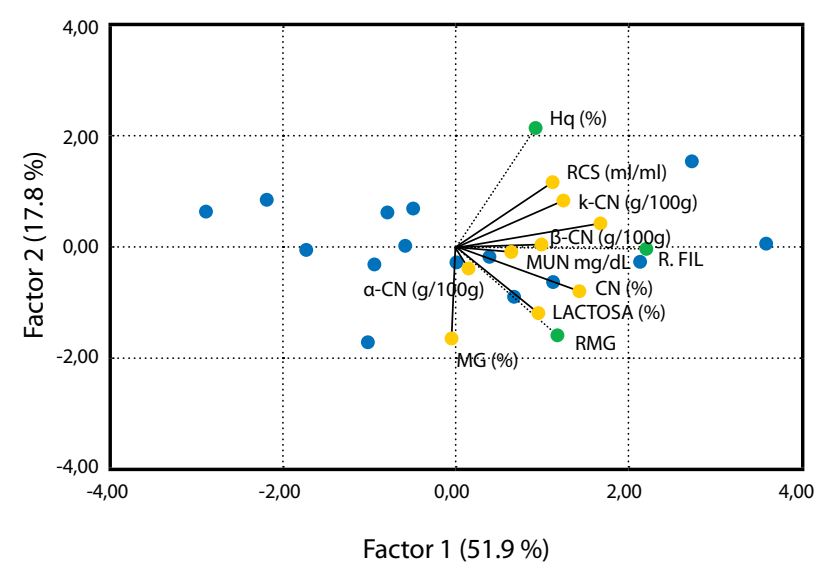

Gráfico 7. Análisis multivariado de mínimos cuadrados parciales de las variables en el Rendimiento FIL, recuperación de materia grasa en queso (RMG) y humedad del queso (Hq [\%]), según parámetros de la leche MUN (urea), CN, $\alpha-\mathrm{CN}, \beta-\mathrm{CN}$ у к-CN, RCS, LACTOSA y MG, en invierno (a) y otoño (b).

Por un lado, se observa que en los quesos elaborados en invierno, la $\beta-\mathrm{CN}, \kappa-\mathrm{CN}$ y la lactosa son los componentes de la leche que afectan positivamente el rendimiento quesero. Por otro lado, se aprecia una influencia negativa en el rendimiento del queso por parte de la urea en leche.

Se muestra una asociación entre la $\alpha$-CN y la recuperación de materia grasa, lo que puede estar asociado a una mejor retención de grasa en la red proteica que forma el queso. No se observó una relación del RCS y el rendimiento quesero en el rango de células somáticas que presentaron las leches utilizadas en estas elaboraciones. Para los quesos elaborados en otoño se incluye además el diámetro de partícula de la caseína, en el que se observa la influencia positiva de la caseína y $ß-\mathrm{CN}$ en el rendimiento quesero; la $\mathrm{k}$ - $\mathrm{CN}$ está más asociada a la humedad y la $\alpha-\mathrm{CN}$ a la recuperación de materia grasa, coincidiendo estos resultados en parte con los obtenidos en invierno. 


\section{Distribución del tamaño de micela de caseína}

No se encontró una correlación entre el D (v0,5) y el D (v0,9) con el rendimiento quesero. El valor medio encontrado de $\mathrm{D}(\mathrm{v} 0,5)$ fue de $334 \mu \mathrm{m}$, variable entre un mínimo de 277 $\mu \mathrm{m}$ y un máximo de $412 \mu \mathrm{m}$. El valor medio de D (v0,9) fue de $674 \mu \mathrm{m}$, variable entre un mínimo de $576 \mu \mathrm{m}$ y un máximo de $577 \mu \mathrm{m}$.

\section{Efecto de la composición de la leche sobre la textura del queso}

En el Gráfico 8 se aprecia la dureza del queso para ambas elaboraciones, expresada según la fuerza aplicada. En la elaboración de invierno no se observan diferencias significativas a tiempo 0 entre los tratamientos estudiados. En la elaboración de otoño los quesos que poseían baja caseína independientemente de las células somáticas poseen en el tiempo 0 mayor dureza.

En ambas estaciones se observa la disminución de la dureza a los 60 días de estudio, lo que corresponde a una proteólisis del queso con la maduración del mismo. En la Tabla 3 se muestra que los quesos con menor porcentaje de proteína presentan menor fuerza, lo que podría deberse a una mayor proteólisis.

Según se observa en la Tabla 3, no hubo diferencias significativas con la masticabilidad, cohesividad y la elasticidad de los quesos estudiados. Se observa una mayor masticabilidad en los quesos que contienen alta caseína, lo cual es razonable ya que está relacionada con la dureza.

\section{Discusión}

\section{Rendimiento}

Los resultados indican que el rendimiento económico es un buen estimativo del rendimiento técnico de la fórmula FIL presentada. El RE es una formulación que requiere medidas a.

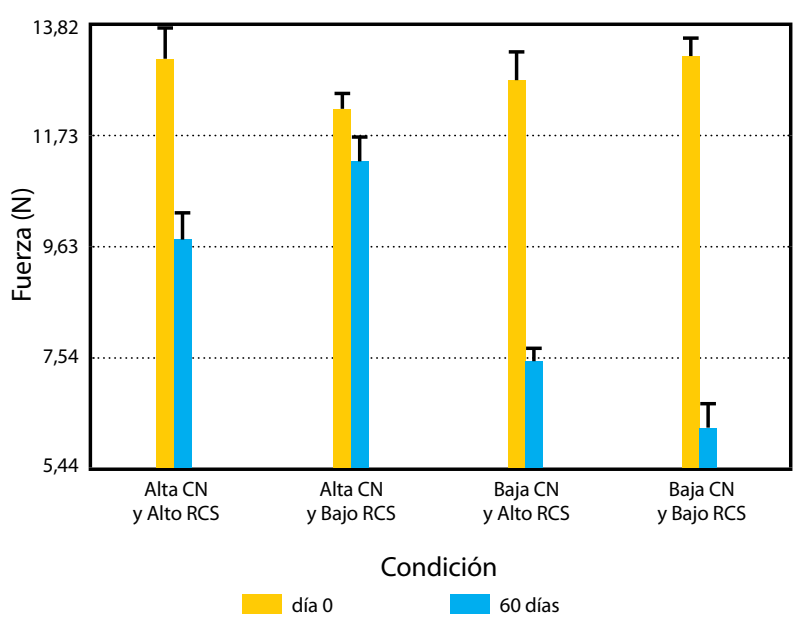

b.

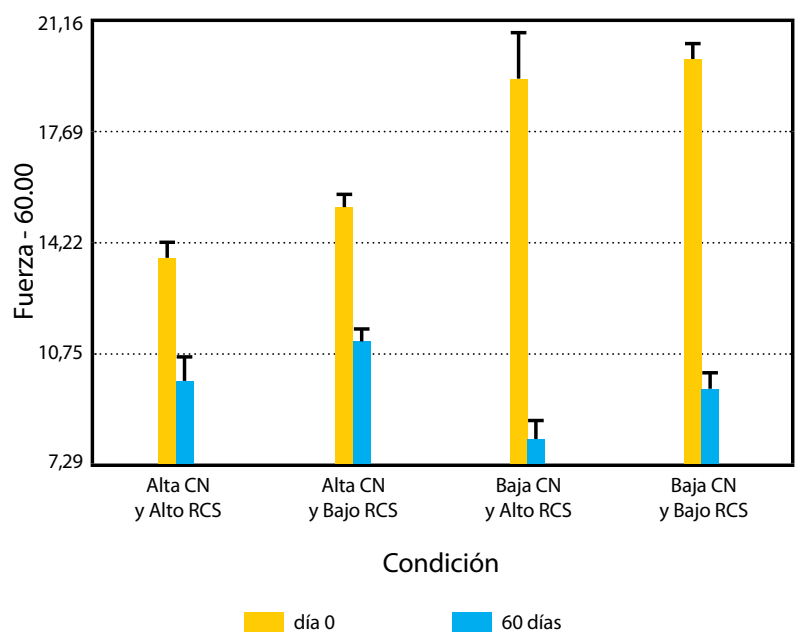

Gráfico 8. Fuerza del queso según condición a tiempo 0 y 60 días de la elaboración de invierno (a) y otoño (b).

\begin{tabular}{|c|c|c|c|c|c|}
\hline $\begin{array}{c}\text { CASEÍNA } \\
\text { Y RCS }\end{array}$ & F (N) & $\begin{array}{c}\text { Adhesividad } \\
\text { (g.sec) }\end{array}$ & Cohesividad & Elasticidad & Masticabilidad \\
\hline $\begin{array}{c}\text { Alta CN } \\
\text { y Alto RCS }\end{array}$ & $9,73+/-0,49^{\mathrm{a}}$ & $-9,56+/-0,88^{\mathrm{a}}$ & $0,99+/-0,01^{\mathrm{a}}$ & $0,96+/-0,01^{\mathrm{a}}$ & $9,39+/-0,38^{\mathrm{AB}^{\mathrm{B}}}$ \\
$\begin{array}{c}\text { Alta CN } \\
\text { y Bajo CS }\end{array}$ & $11,20+/-0,43^{\mathrm{a}}$ & $-11,39+/-0,89^{\mathrm{a}}$ & $0,97+/-0,01^{\mathrm{a}}$ & $0,96+/-0,01^{\mathrm{a}}$ & $10,3+/-0,39^{\mathrm{A}}$ \\
$\begin{array}{c}\text { Baja CN } \\
\text { y Alto RCS }\end{array}$ & $7,48+/-0,49^{\mathrm{b}}$ & $-12,90+/-1,03^{\mathrm{a}}$ & $0,98+/-0,01^{\mathrm{a}}$ & $0,96+/-0,01^{\mathrm{a}}$ & $7,06+/-0,45^{\mathrm{B}}$ \\
$\begin{array}{c}\text { Baja CN } \\
\text { y Bajo RCS }\end{array}$ & $6,22+/-0,42^{\mathrm{b}}$ & $-11,12+/-1,01^{\mathrm{a}}$ & $0,99+/-0,01^{\mathrm{a}}$ & $0,95+/-0,01^{\mathrm{a}}$ & $5,79+/-0,38^{{ }^{\mathrm{B}}}$ \\
\hline
\end{tabular}

Tabla 3. Parámetros de textura en los quesos en la elaboración de invierno a los 60 días.

Medias con letras minúsculas con una letra común en la misma columna no son significativamente diferentes $(p>0,05)$. Medias con letras mayúsculas con una letra común en la misma columna no son significativamente diferentes ( $p>0,0628)$. 
de peso del queso y la leche, y es comúnmente utilizado por las industrias, no así el FIL, que requiere la realización de técnicas y equipos de más valor para su determinación. El uso del rendimiento ajustado no se correlaciona con el rendimiento FIL ni con el económico. El conocimiento de estas relaciones podría ayudar a las industrias a elegir qué ecuaciones tomar para el cálculo del rendimiento.

\section{Efecto de la caseína y el RCS en leche sobre el rendimiento quesero}

En la escala piloto se obtiene en rendimiento económico un $7 \%$ de aumento en invierno y un $11 \%$ en otoño, lo que confirma la variación estacional. En escala industrial ambas empresas obtuvieron menor aumento de rendimiento en el mes de invierno. Este resultado dado en ambas escalas podría estar relacionado al sistema productivo de cada época del año (considerando como sistema la alimentación y sanidad animal).

El mayor rendimiento ( $9 \%$ ) en escala piloto es obtenido cuando se tiene alta caseína. Si bien se obtuvo a nivel industria un promedio de aumento de rendimiento del $(\sim 10 \%)$ al elaborar quesos con leches de alta caseína en comparación al promedio de planta, se visualizó que la empresa $B$ posee valores mayores de aumento, lo cual puede deberse a diversos factores, no solo de la leche sino también de prácticas de elaboración a nivel industrial.

Se confirma a escala industrial los resultados obtenidos a escala piloto y se puede afirmar que para quesos Dambo elaborados en estas condiciones y con la leche utilizada el rendimiento fue entre un 9 y $10 \%$ mayor al utilizar leches de alto contenido de caseína. Esto concuerda con lo demostrado por varios autores en cuanto a que el contenido de caseína está directamente relacionado con el contenido del queso (Walstra, et al., 2006; McSweeney, et al., 2007; Abd El-Gawad y Ahmed, 2011).

El mayor rendimiento existe según estos estudios al presentar mayor caseína y menor RCS (Tabla 1), y esta es la situación en la que se tiene la mayor recuperación de materia grasa en el queso (Gráfico 2), lo cual se mantiene en el tiempo de estudio. Por esto se podría considerar que el mayor rendimiento obtenido puede deberse a una mayor retención de la materia grasa de la leche en la red proteica del queso.

Las leches con alta caseína y alto recuento de células somáticas fueron las que presentaron mayor humedad en los quesos (Gráfico 3) en otoño. Vianna y equipo (2008) concluyeron en un estudio de queso Prato (queso tipificado como de pasta lavada al igual que el Dambo) que altos niveles de RCS (785.000 células $/ \mathrm{mL}$ ) afectan las bacterias ácido lácticas, los psicótropos y el recuento de hongos y levaduras, presentando un aumento en la humedad y un menor contenido de grasa, pero una menor aceptación por parte del consumidor.

En escala piloto (Gráfico 4) los quesos con alto RCS y baja $\mathrm{CN}$ son los que recuperan menor cantidad de proteínas. Esto coincide con trabajos que demuestran que la leche con alto contenido de células conduce a una mayor pérdida de proteína en la fabricación de queso y, por lo tanto, a un menor rendimiento del queso, y RCS mayores a 500.000 células/mL conducen a una disminución del rendimiento (Abd El-Gawad y Ahmed, 2011).

En escala industrial ambas empresas (Gráficos 5 y 6) también indican un aumento del rendimiento referido a una mayor retención de materia grasa de la leche en el queso, lo que es concordante con los resultados hallados a escala piloto.

\section{Efecto de distintos componentes de la leche en el rendimiento quesero}

Según estudios realizados por otros autores, la $\kappa-\mathrm{CN}$ desempeña un papel muy importante tanto en la micela de caseína como en la elaboración de quesos. A su vez, es la que limita el proceso de asociación proteica dentro de la micela, además de determinar el tamaño final y estabilidad de la misma (Kruif, et al., 2012; Huppertz, et al., 2006), siendo una de las caseínas que influyen fuertemente en el rendimiento del queso. Abd El-Gawad y Ahmed (2011) determinaron que la $\kappa$-CN tiene repercusiones sobre el tamaño de las micelas de caseína y sobre las propiedades de coagulación de la leche, dando una cuajada más firme y capaz de retener una mayor cantidad de sustancias, aumentando así el rendimiento del queso. En este artículo se consignaron resultados similares en cuanto a la influencia de la $\mathrm{K}$-caseína en el aumento del rendimiento del queso, pero no se hicieron inferencias sobre el tamaño de la partícula. Otros autores han reportado influencia en la coagulación y un aumento en el rendimiento del queso por la к-CN (Ikonen, et al., 1999; Wedholm, et al., 2006), principalmente por el alelo bb de la $\kappa-\mathrm{CN}$ (Bonfatti, et al., 2011). St-Gelais y otros (2005) reportan a $\alpha-\mathrm{CN}$ y $\beta-\mathrm{CN}$ como constituyentes básicas de la microestructura del queso y Bonfatti et al. (2011) sugieren más estudios sobre la $\beta-C N$. A su vez, se ha reportado en estudios sobre la influencia del tamaño de micelas de caseína nativas sobre el rendimiento quesero que su tamaño está influenciado por el régimen de alimentación de los rodeos, sus genotipos de as1-CN y к-CN, el pH (Devold, et al., 2000) y la variación estacional. Glantz et al. (2010) estudiaron la influencia del tamaño de la caseína en la formación de geles con renina, concluyendo que un menor tamaño de micela de caseína mejora las propiedades de gelificación, lo que podría optimizar el paso inicial en el procesamiento del queso. En este estudio no se verifica su influencia, lo que requiere mayor conocimiento de los rodeos estudiados y sus efectos.

La salud de la ubre es otro de los factores que afectan la calidad de la leche y, por consiguiente, la producción de queso. El alto contenido de RCS redunda en un mayor tiempo de coagulación de la leche, presentando un coágulo más débil, lo que conduce a una mala sinéresis y a un bajo rendimiento quesero (Marino, et al., 2004). Sin embargo, en el rango de RCS de este estudio realizado en el queso tipo Dambo en la planta piloto no se asocia una relación entre el RCS y el rendimiento quesero en ninguna de las dos elaboraciones realizadas (Gráfico 7). Los rangos de células somáticas de las leches estudiadas fueron desde 100.000 hasta 612.000 células/mL. En los rangos que se consideraron en este estudio la incidencia de los valores de caseína y los tipos de caseína tuvieron mayor incidencia en el rendimiento que los RCS. Se han realizado estudios en queso Prato, similar al Dambo, en los que se elaboraron quesos con bajo RCS (170.000 células/ $\mathrm{mL}$ ) y alto RCA ( 800.000 células $/ \mathrm{mL})$, concluyendo que un alto recuento de células somáticas aumenta el tiempo de coagulación y provoca pérdidas económicas para la industria (Mazal, et al., 2007).

En cuanto a la urea en leche (MUN), en la elaboración de otoño (Gráfico 7 a y b) se identificó un efecto contrario entre las estaciones estudiadas, por lo que habría que enfocar 
más estudios en este tema. Podría haber un efecto estación debido a la alimentación ofrecida a los rodeos lecheros en las diferentes estaciones, pero no es posible confirmarlo con los datos obtenidos. Según Moharrery (2004), al aumentar la urea en leche se produce una disociación parcial de la caseína, calcio y fosfato hacia la fase soluble. En particular, altas concentraciones de urea son causa directa o indirecta de problemas como un incremento en el tiempo de coagulación, la formación de una cuajada más débil y menos estructurada, el desarrollo prematuro de fermentaciones irregulares y cambios en la proteólisis de la masa. Si bien no hay muchos reportes sobre los efectos de la urea de la leche en quesos, se encontró que está relacionada con la composición cinética de acidificación y textura en Reblochon cheeses (Martin, 1997), y que en leche de cabra el tiempo necesario para la coagulación y organización de la cuajada fue mayor para la leche de alto tenor de urea (Allocati, 2002).

\section{Textura}

Si bien existen varios estudios de reología del gel en quesos, los estudios de textura son más enfocados a cambios en procesos que a la composición de la leche en sí misma. Kamleh y otros (2006) relacionaron una mayor dureza del queso Baladi cuando se tiene una mayor concentración de sólidos totales. Los efectos de textura en los quesos dependen de muchas variables, entre ellas el tamaño de micelas de caseína que al ser modificado cambia la textura de los quesos (Sandra, et al., 2004a; Hnosko, 2007; Escobar, et al., 2011), así como los fermentos y cuajos utilizados. La disminución de la fuerza del queso a los 60 días en ambas estaciones del año puede deberse a que las enzimas proteolíticas presentes en los quesos van actuando y produciendo una proteólisis y disminuyendo así la dureza del queso con la maduración. La masticabilidad es el producto de la fuerza por la cohesividad y por la elasticidad, dado que las dos últimas fueron independientes de las condiciones el cambio de masticabilidad está directamente relacionado con la dureza del queso.

Aunque en este estudio se mantuvieron constantes las condiciones de elaboración, para evaluar solo el efecto de la leche son necesarios más estudios.

\section{Conclusiones}

El rendimiento quesero es un factor importante para la industria por lo que representa en la economía, sobre todo en un país exportador. La ecuación de rendimiento económico que es habitualmente utilizada por la industria láctea es un buen estimativo del rendimiento técnico.

Los quesos producidos con leche que contiene alta caseína y bajo RCS presentan mayor rendimiento con una mayor recuperación de materia grasa en el queso. Por un lado, estos factores pueden ayudar a la industria a evaluar el pago de la leche y, por otro lado, pueden guiar al productor a una producción ajustada a los intereses de la industria.

La caseína es el componente de la leche que presenta mayor influencia positiva en el rendimiento quesero en los rangos estudiados, lo cual coincide con la literatura de referencia a nivel mundial. Sin embargo, existen otros resultados que resultan divergentes a lo propuesto por otras investigaciones. Un ejemplo de ello son los resultados encontrados por la influencia de la urea, los cuales según la bibliografía de referencia requieren una profundización en el estudio de la urea a diferentes niveles.

A su vez, se obtiene una influencia positiva de la $\kappa$-caseína y de la $\beta$-caseína en el rendimiento quesero, lo que sugiere el estudio de los perfiles proteicos de los rodeos en el país y de su genética que permita buscar una relación con la leche y con el rendimiento del queso.

Se identificaron parámetros de calidad de leche que permiten a la industria guiar al productor hacia la obtención de leche mejorada para la producción de queso, lo cual redunda en un beneficio para toda la cadena láctea. También se obtuvieron resultados que pueden permitir futuros estudios para la evaluación sobre la logística de recolección de leche y su destino final. Existen otros factores como los tamaños de la micela de caseína y del glóbulo de grasa, el equilibrio mineral, la urea y la genética de los rodeos lecheros que resulta crucial incorporar en otros estudios con el fin de continuar optimizando la producción de la industria láctea nacional.

\section{Reconocimientos}

A todo el personal que contribuyó a este proyecto por parte de las distintas instituciones, CLALDY S.A. y PILI S.A., INIA, LATU y UdelaR. Especialmente a: V. Friessen, H. Klanssen, A. González, J. Cabrera E. De Torres, E. Gianneecchini, E. Favre, L. Casas y J. Cea. A los 30 productores de las empresas lácteas y extensionistas de las industrias, así como al personal directivo de las industrias y empresas que apoyaron el proyecto. A visitantes extranjeros: F. Harte de Pennsylvania State University, USA P. Juliano de CSIRO Australia, A. Gauna de Clerici Sacco Group y J. Berterreche.

Los autores agradecen a la Agencia Nacional de Investigación e Innovación (ANII) por la financiación del proyecto de alianzas gracias al cual se desarrolló esta publicación.

\section{Referencias}

Abd El-Gawad, M.A.M, Ahmed, N.S., 2011. Cheese yield as affected by some parameters review. En: Acta Sci. Pol., Technol. Aliment, 10(2), pp.131-153.

Allocati, P., Gonzales, J.H., Ceballos, M.E., Cassu, M.E. y Danelon, J.L., 2002. Contenido de urea en leche de cabra e Impacto de la calidad en leche de cabra. En: Revista Argentina de Lactología. (21), pp.9-22.

Bonfatti, V., Cecchinato, A., Gallo, l., Blasco, A. y Carnier, P., 2011. Genetic analysis of detailed milk protein composition and coagulation properties in Simmental cattle. En: Journal of Dairy Science, (94), pp.5183-5193.

Bonizzi, I.; Buffoni, J.N., y Feligini, M., 2009. Quantification of bovine casein fractions by direct chromatographic analysis of milk. Approaching the application to a real production context. En: Journal of Chromatography A, 1216, pp.165-168.

Devold, T. G., Brovold, M. J., Langsrud, T. y Vegarud, G. E., 2000. Size of native and heated casein micelles, content of protein and minerals in milk from Norwegian Red cattle Effect of milk protein polymorphism and different feeding regimens. En: International Dairy Journal, 10, pp.313-323.

Escobar, D., Clark, S., Ganesan, V., Repiso, L., Waller, J. y Harte, F., 2011. High pressure homogenization of raw and pasteurized milk modifies the yield, composition 
and texture of queso fresco cheese. En: Journal of Dairy Science, 94, pp.1201-1210.

Glantz, M., Devold, T. G., Vegarud, G. E., Lindmark Månsson, H., Stålhammar, H. y Paulsson, M., 2010. Importance of casein micelle size and milk composition for milk gelation. En: Journal of Dairy Science, 93, pp.1444-1451.

Hnosko, J. M., 2007. High hydrostatic pressure treatment reduces levels of Listeria innocuain queso fresco. Washington: WSU.

Huppertz, T., Fox, P. F., Kruif, K. G., y Kelly, A. L., 2006. High pressure-induced changes in bovine milk proteins: A review. En: Biochimica et Biophysica Acta, 1764, pp.593-598.

Ikonen, T., Ahlfors, K., Kempe, R., Ojala, M., and Ruottinen, O., 1999. Genetic parameters for the milk coagulation properties and prevalence of non-coagulating milk in Finnish dairy cows. En: Journal of Dairy Science, 82, pp.205-214.

International Dairy Federation, 1993. Cheese yield and factors affecting its control. IDF.

International Organization for Standardization, 2004. ISO 1735 (IDF 5): Cheese and processed cheese products - Determination of fat content - Gravimetric method (Reference method). Ginebra: ISO.

International Organization for Standardization, 2004. ISO 5534 (IDF 4): Cheese and processed cheese - determination of the total solids content (Reference method). Ginebra: ISO.

International Organization for Standardization, 2010. ISO 1211 (IDF1): Milk - Determination of fat content Gravimetric method (Reference method). Ginebra: ISO.

International Organization for Standardization, 2010. ISO 6731 (IDF 21): Milk, cream and evaporated milk. Determination of total solids content (Reference method). Ginebra: ISO.

International Organization for Standardization, 2012. ISO/TS 22113 (IDF/RM 204): Milk and milk products - Determination of the titratable acidity of milk fat. Ginebra: ISO.

International Organization for Standardization 2001. ISO 8968 (IDF 20): Milk - Determination of nitrogen content - Part 1: Kjeldahl method, Part 2: Block-digestion method. Ginebra: ISO.

Kamleh, R., Tannous, R. y El Maydaa, E., 2006. Cows milk quality in two regions in Lebanon and its effect on Baladi (local)cheese quality. En: Journal of Food Agric. \& Environment, 4(2), pp.75-77.

Kruif, C.F., Huppertz, T., Urban, V.S., y Petukhov, A.V., 2012. Casein micelles and their internal structure. En: Advances in Colloid and Interface Science, 171-172, pp.36-52.

Marino, P., Considine, T., Sevi, A., McSweeney, P.L.H., y Kelly, A.L., 2004. Contribution of proteolytic activity associated withsomatic cells in milk to cheese ripening. En: International Dairy Journal, 15, pp.1026-1033.

Martin, B., Coulon, J.B., Chamba, J.F., y Bugaud, C., 1997. Effect of milk urea content on characteristics of matured Reblochon cheeses. En: Lait, 77, pp.505-514.

Mazal, G., Vianna, P. C. B., Santos, M. V., y Gigante, M. L., 2007. Effect of somatic cell count on prato cheese composition. En: Journal of Dairy Science, 90, pp.630-636.

McSweeney, P. L. H., 2007. Cheese problems solved. Abington: Woodhead Publishing Limited.

Moharrery, A., 2004. Investigation of different levels of RDP in the rations of lactating cows and their effects on MUN, BUN and urinary $\mathrm{N}$ excretion. En: Italian Journal of Animal Science, 3(2), pp.157-165.

Ng-Kwai-Hang, K. F., 1998. Genetic polymorphism of milk proteins: Relationships with production traits, milk composition and technological properties. En: Canadian Journal of Animal Science, 78, pp.131-147.

Ozymek, L. y Kennelly, J., 1993. The effect of seasonal and regional variation in milk composition on potential cheese yield. En: International Dairy Federation. Proceedings of the IDF seminar on cheese yield and factors affecting its control. Brussels: IDF. (Special Issue No. 9402), pp.95-100.

Sandra, S., Stanford, M. A., y Goddik, L. M., 2004. The use of highpressure processing in the production of Queso Fresco cheese. En: Journal of Food Science, 69, pp.153-158.

Santos, M.V. y Barbano, D.M., 2003. Effect of somatic cell count on proteolysis and lipolysis in pasteurized fluid milk during shelf-life storage. En: Journal of Dairy Science, 86, pp.2491-2503.

St-Gelais, D. y Hache, S., 2005. Effect of b-casein concentration in cheese milk on rennet coagulation properties, cheese composition and cheese ripening. En: Food Research International, 38, pp.523-531.

Uruguay XXI, 2012. Informe de comercio exterior [En línea]. Montevideo: Uruguay XXI. [Consulta: abril de 2014]. Disponible en: http://www.uruguayxxi.gub.uy/wp-content/ uploads/2011/11/Informe-de-Comercio-Exterior-deUruguay-FINAL-A\%C3\%B1o-2012.pdf.

Vianna, P. C. B., Mazal, G., Santos M. V., A. Bolini, H. M. y Gigante, M. L., 2008. Microbial and sensory changes throughout the ripening of prato cheese made from milk with different levels of somatic cells. En: Journal of Dairy Science, 91, pp.1743-1750.

Walstra, P., Wouters, J.T.M. y Geurts, T.J., 2006. Dairy science and technology. 2da. ed. New York: Taylor \& Francis.

Wedholm, A., Larsen, L. B., Lindmark-Mansson, H., Karlsson, A. H. and Andrén, A., 2006. Effect of protein composition on the cheese-making properties of milk from individual dairy cows. En: Journal of Dairy Science, 89, pp.3296-3305. 